\section{PRODUÇÃO ARTÍSTICA NA EDUCAÇÃO DO CAMPO CAPIXABA UMA EXPERIÊNCIA DE APRENDIZAGEM SIGNIFICATIVA}

\author{
ARTISTIC PRODUCTION IN \\ CAPIXABA FIELD EDUCATION \\ AN EXPERIENCE IN \\ MEANINGFUL LEARNING
}

\author{
Elcie F. Salzano Masini ${ }^{1}$ \\ Fabricia Alves da Silva Pimentel ${ }^{2}$
}

Resumo: Relato da experiência de uma educadora do campo, do estado do Espírito Santo, mestranda de uma pós-graduação interdisciplinar, na cidade de São Paulo. Descrição da vivência na metrópole almejada para usufruir benefícios culturais, das próprias inquietações frente aos conceitos depreciativos sobre a cultura camponesa e o desejo de ampliar olhares sobre as possibilidades de vivências e descobertas dos espaços de vida e de produções culturais, artísticas e sociais do campo capixaba. A busca dos significados da produção capixaba e os valores descobertos da sua expressão artística revelaram a percepção e compreensão do seu próprio mundo. $\mathrm{O}$ desvelar da produção artística no Campo Capixaba propiciou à educadora e mestranda uma Aprendizagem Significativa.

No esforço de ampliar conhecimentos, na expectativa de aprofundamento de estudos e de conhecimentos de diferentes áreas, da dúvida sobre certezas construídas, a educadora camponesa resgatou a

\footnotetext{
${ }^{1}$ Dra. em Psicologia. Professora do Programa de pós-graduação Educação Arte e História da Cultura da Universidade Presbiteriana Mackenzie. Pesquisadora nível 1 em Produtividade em Pesquisa do CNPq. E-mail: delcie66@yahoo.com.br

2 Pedagoga. Professora e coordenadora de classes multisseriadas na educação do campo no Espírito Santo. Mestranda do Programa de pós-graduação Educação Arte e História da Cultura da Universidade Presbiteriana Mackenzie. E-mail: delcie66@yahoo.com.br
}

complexidade do campo. A partir dos significados dessa vida compreendeu e elaborou o que apreendeu da complexidade da vida da metrópole e construiu novos significados reiterando como o conhecimento vai sendo adquirido à medida que novas informações são ancoradas em representação, conceitos e ideias que tem disponíveis em sua estrutura cognitiva (AUSUBEL, 1963).

Palavras-Chave: Representação; Conhecimento; Campo

Abstract: Report about an experience of a field educator of the state of Espirito Santo, student of a Master in the city of São Paulo. Description of her life in the desired metropolis to enjoy their cultural benefits; of her own inquietudes in face of the depreciative concepts about the field culture and the desire to know more about possibilities of life and discoveries of cultural spaces of social and artistic productions of the field capixaba. The search of meanings of capixaba production and the values discovered of their artistic expression revealed their perception and comprehension of their own world. To unveil the artistic production in the Capixaba Field offered to the educator an Meaningful Learning. On the effort to know more, with the expectation to study deeply in different areas of knowledge, from the doubt on constructed believes, the field educator recued the complexity of the field. Based on the meanings of this life she understood an elaborated what had learned of the complexity of the life of the metropolis and she constructed new meanings reassuring that the knowledge has been acquired when knew informations are based on representations, concepts and ideas that one has in his cognitive structure (AUSUBEL, 1963).

Keywords: representations; knowledge; field 


\section{DIVERS@!}

\section{Introdução}

Este é o relato da experiência de uma educadora na capital do estado de São Paulo, em busca do aprimoramento da sua formação profissional. Alguns meses, como aluna de pós-graduação em um Mestrado interdisciplinar - Educação, Arte, História da Cultura - ampliaram as intenções iniciais, e a convivência com professores e colegas, em um novo espaço, transformaram algumas certezas em muitas dúvidas e desafios a serem superados.

Algumas situações pareciam impossíveis, pois, os pensamentos a respeito de temas difíceis de serem entendidos não paravam de se complicar a cada novo estudo, a cada nova conversa. Entrar no universo da metrópole e desfrutar os benefícios desse local parecia forçar a camponesa a querer aí permanecer e usufruir de tudo que ele podia oferecer. Era a expectativa: de aprofundamento de estudos; da ruptura total com as certezas construídas; da ampliação da percepção dos espaços, pessoas; de estender conhecimentos a diferentes áreas.

Não havia mais possibilidade de ver, ouvir, sentir, tatear e falar sobre as coisas, pessoas, sensações, os gostos, as músicas e tantas outras possibilidades, sem uma nova percepção e reflexão a respeito de cada uma delas.Após algum tempo mergulhada no universo acadêmico e no contato com ricas experiências em alguns grupos, foi possível experimentar outras nuances de sons e sabores na percepção e nos conhecimentos já adquiridos: entrar em contato com as próprias inquietações a respeito de conceitos depreciativos da cultura camponesa e experimentar o desejo de ampliar olhares sobre as possibilidades de vivencias e descobertas sobre o espaço de vida e de produções culturais, artísticas e sociais do campo capixaba.

\section{Os significados da produção}

\section{capixaba: valores descobertos}

Algumas dúvidas surgiram referentes ao valor atribuído às produções artísticas, desenvolvidas em espaços não contemplados pela divulgação, reconhecimento público e validação acadêmica. Emergiram novas indagações e inquietações: Para quem é importante o reconhecimento ou validação das produções culturais e artísticas do campo capixaba? A quem cabe o reconhecimento ou validação dessas produções? Perguntas essas que remeteram a afirmações de críticos de arte consagrados como Jianou (1970, p. 22): "A arte segundo Rodin não é um meio de evasão, mas uma das vias que remete ao conhecimento da realidade" ${ }^{3}$ (tradução nossa).

\footnotetext{
3 "L'art, selonRodin, nèst pas um moyen d'évasin, mais une des voies qui mènent à la connaissance de la réalité." (Original).
} 
Cabia, pois, ouvir aqueles que habitam o mesmo contexto sobre o que tinham a dizer de sua realidade. Eram, pois, os participantes de uma associação de artesanato em uma comunidade capixaba que poderiam responder àquelas perguntas. $\mathrm{O}$ desejo de entender o que era realmente importante para esse grupo levou a nova visita a uma associação de artesanato. Observou-se que para as rendeiras ali presentes o que valia no processo de criação era a possibilidade de traduzir nas produções um pouco do mundo em que viviam.Pereira e Nardin (2008) reiteram essa base da criação artística da tecelagem no cotidiano, ao afirmarem:

Essas informações favorecem nossa compreensão sobre o artesanal revelar a cultura das pessoas envolvidas nesse processo como também as características geopolíticas, o meio físico e humano, especialmente no que se refere ao conhecimento manifesto na materialidade cultural, produzidas por determinados segmentos sociais.

Um grupo de camponeses no município de Nova Venécia no Espírito Santo mantinha viva a tradição da tecelagem com a taboa ${ }^{4}$.O centro de cultura do município promovia atividades de incentivo ao trabalho cooperativo e as mulheres camponesas desenvolviam em

\footnotetext{
${ }^{4}$ Taboa é uma planta hidrófita típica de brejos, manguezais, várzeas e outros espelhos de águas. Mede cerca de dois metros e na época de reprodução apresenta espigas da cor café, contendo milhões de sementes que se espalham pelo vento.
}

grupo o trabalho, desde a extração da taboa no campo até a tecelagem na sede da associação ou no pátio da igreja na comunidade São Luiz Gonzaga, onde também eram realizados palestras, cursos de aperfeiçoamento sobre a produção e comercialização dos produtos. A cooperativa é conhecida como ArtBoa e conta com o trabalho de um grupo diverso de mulheres entre 16 e 70 anos, o que enriquece o trabalho como o depoimento de uma artesã que disse "juntar a criatividade das meninas novas para inventar produtos à experiência das mulheres mais velhas para retirar as melhores taboas e fazerem produtos diferentes, bonitos e de boa qualidade" (Dona Dorvina). Independente das definições e das tendências referentes a Arte, para o grupo de camponeses, a conceituação acadêmica de arte era dispensável, pois, toda criação emergia de tradições familiares, de conhecimentos transmitidos pela comunidade, além de muita alegria, emoção, cooperação e respeito para com as produções individuais e coletivas. Em uma visita a exposição de arte no Instituto Tomie Ohtake, em São Paulo, intitulada "Teimosia da Imaginação", em 2012, houve a oportunidade de apreciar a produção de artistas camponeses de várias regiões brasileiras e entender o que cada um deles vivenciava no dia a dia na busca da matéria-prima (retirada da natureza), e 


\section{DIVERS@!}

verificar que as características apresentadas no documentário sobre o estilo de vida, de campo e as características de trabalho dos expositores era idêntica às encontradas no grupo de artesãs ArtBoa.

A ArtBoa é a Associação de Artesãos de Artesanato em Taboa, criada em agosto de 2011, com o objetivo de organizar o trabalho e orientar administrativamente os artesãos na comercialização e aperfeiçoamento do seu artesanato. Composta por homens e mulheres com idade entre 16 e 70 anos a associação se destaca pela criatividade na produção das peças e cooperação entre os associados na troca de experiência tanto na retirada da matéria-prima quanto na técnica de trançar as fibras. Em depoimento apresentado no documentário da exposição "Teimosia da Imaginação", o Sr. Antonio Dedé, artesão de Maceió, relatou que a alegria é uma característica do trabalho, pois, "uma peça mal-humorada não chama atenção do público". Talvez isso justifique tanta alegria e simplicidade na fala e a grandeza das peças produzidas por ele que cria suas esculturas em troncos e galhos de árvores que encontra na natureza. Estas madeiras são resgatadas de áreas de "derrubadas". Com isso o Sr. Antonio Dedé deixou claro que não corta árvores para produção de suas esculturas, ao contrário, ele utiliza os troncos e galhos que encontra secos pelo chão. Dessa matéria-prima o escultor dá vazão ao imaginário criativo e produz suas
peças.Pensando a realidade do campo capixaba, as comunidades rurais produzem belas e desconhecidas peças de artesanato e desfrutam de algumas composições de poesias cantadas nas modas de viola.

\section{A expressão artística - percepção e compreensão do próprio mundo}

Situar o significado da produção capixaba, requer resgatar concepções que contrapõem Arte e Artesanato.Salgado e Franciscatti (2012, s/p) retomaram Gullar $(1994)^{5}$, que diferenciou a arte do artesanato, ao afirmar que a arte buscava novas formas e estilo enquanto o artesanato era conservador e repetitivo; retomaram Andrade (1938) ${ }^{6}$ que, também, se referia ao artesanato como arte menor, assinalando, porém, que este autor enfatizava que o objeto artesanal podia tornar-se um testemunho, uma revelação da relação homem e sociedade, ao afirmarem: "É na tensão entre repetição e criação que Andrade (1938) considera a possibilidade da revelação do objeto artesanal: o que desponta de criação em meio à repetição contém a rebeldia e a transgressão da própria repetição".

${ }^{5}$ GULLAR, F. O artesanato e a crise da arte. Revista de cultura e vozes, Petrópolis, RJ, v. 88, n. 4, p. 7-12, jul/ago 1994.

${ }^{6}$ ANDRADE, M. de. O artista e o artesão: aula inaugural dos cursos de filosofia e história da arte, do instituto de artes. São Paulo, SP: Universidade do Distrito Federal, 1938. 


\section{DIVERSQ!}

As maiores dificuldades para alcançar o sentido da produção capixaba estão, pois, em desconstruir conceitos preexistentes, perceber novas possibilidades e novos caminhos trilhados, livres dos impedimentos de experiências anteriores carregadas da necessidade de validação acadêmica, distante da expressividade e produção no espaço camponês.

Ao considerar a arte como a língua do mundo, e como linguagem que desconhece fronteiras, para se expressar, faz-se necessário analisar o local em que essa linguagem artística se manifesta.Sendo a linguagem artística aquela que traz consigo a qualidade de ser a linguagem cuja leitura e produção existe no mundo todo, e para todo mundo, vale refletir sobre os espaços da arte nas comunidades camponesas.

A comunicação entre as pessoas e as leituras de mundo não se dão apenas por meio da palavra. Muito do que se sabe sobre o pensamento e o sentimento das mais diversas pessoas, povos, países, épocas, são conhecimentos comunicados por meio da música, teatro, poesia, pintura, dança, cinema, entre outros.

Uma análise reflexiva da história da arte remete à própria história da humanidade. A arte egípcia era ligada ao espírito, a arte grega à inteligência. A arte indígena no Brasil se manifesta a partir de características culturais como a pintura dos corpos como adorno e também como forma de se defender do sol, dos insetos e dos maus espíritos, entre tantas outras características de cada tribo.Outra forma de manifestação da arte indígena é a cerâmica, que sem perder a beleza e a perfeição dos detalhes e cores, se destacam pela sua utilidade.

A partir de 1530, aproximadamente, com a colonização portuguesa no Brasil, os índios e os negros, sob o comando dos religiosos e dos mestres vindos de terras distantes, aprenderam a trabalhar o barro, a madeira e a pedra. Perceber e compreender a expressão artística, como ficou exposto, exige consideração à complexidade na qual está inserido o homem no mundo que habita.

\section{Produção artística no Campo Capixaba: uma Aprendizagem Significativa}

A concepção de complexidade de Morin (2007) lança luz para compreensão das condições requeridas para a produção artística. Assinala a relevância de se considerar a complexidade do mundo que se habita. Complexidade entendida como o tecido dos acontecimentos, ações, interações, retroações, determinações e acasos que constituem o contexto social. Situado nesse tecido dos acontecimentos em suas ações, interações, retroações e determinações, cada indivíduo vai integrando e organizando informações em 


\section{DIVERS@!}

um complexo processo, no qual amplia sua percepção e compreensão e expressa os seus próprios.

Ausubel (1963) reiterou essa concepção de complexidade ao refletir sobre os caminhos a serem oferecidos para que a capacidade de perceber, compreender, elaborar, fosse facilitada em situação de educação formal. Embasado em sua ampla experiência, de psiquiatra clínico e pesquisador sobre desenvolvimento humano, buscou sistematizar os princípios que propiciam ao ser humano situar - se no mundo, organizando sua experiência e atribuindo significados à realidade em que se encontra. Assim, enraizada no vivido, Ausubel construiu a Teoria da Aprendizagem Significativa (TAS), que evidencia como o conhecimento vai sendo adquirido à medida que o ser humano se situa no mundo, relacionando novas informações com representações, conceitos e ideias que já dispõe na sua estrutura cognitiva.

A originalidade da Teoria da Aprendizagem Significativa é a ênfase ao processo relacional do sujeito, situado em seu contexto, com pessoas e objetos que o cercam. Sujeito, conforme Morin (1996, 2008), que depende do meio biológico, social e cultural para se tornar autônomo e auto e eco organizado. $\mathrm{O}$ sujeito se constrói pela noção de indivíduo do ponto de vista biológico e necessita de uma dimensão cognitiva indispensável à vida, referente ao ato pelo qual se coloca no centro do próprio mundo, para com ele lidar consigo mesmo considerando-o, preservando-se, protegendo-se. É sujeito aquele que pensa por conta própria, por si mesmo e para si mesmo, que permite agir no universo exterior, assim como no próprio universo interior, e reconhecê-los. Ser Sujeito é um dos requisitos primeiros para realizar uma aprendizagem significativa.

A produção artística do camponês capixaba expressa sua percepção e compreensão do que está ao seu redor e revela seus próprios significados, frutos de um processo puramente idiossincrático.Alcançar o significado dessa pessoa, em sua produção artística, requer atenção e abertura à suas manifestações, e consideração ao seu contexto social, imbricado em acontecimentos, ações, interações, retroações, determinações e acasos que o constituem.

O homem do campo, como o da cidade, vive no emaranhado de hábitos individuais e grupais, de valores, atitudes, concepções, buscando registrar o que aí ocorre, sem, porém, dissolver problemas, ocultar ambiguidades e incertezas do conhecimento.

As concepções desses dois autores contribuíram para dissipar dúvidas de uma educadora camponesa e ofereceram apoio 
para enfrentar desafios e as próprias inquietações a respeito de conceitos depreciativos da cultura camponesa. A concepção de complexidade de Morin (2007) iluminou a relevância de considerar a complexidade do mundo que se habita, ampliando a própria percepção, compreensão e expressividade, situada no tecido dos acontecimentos a respeito. Ausubel (1963) evidenciou como o conhecimento vai sendo adquirido à medida que o ser humano enraizado no vivido, amplia seus significados e compreensão sobre o mundo em que se situa.

No esforço de ampliar conhecimentos, na expectativa de aprofundamento de estudos e de conhecimentos de diferentes áreas, da dúvida sobre certezas construídas, a educadora camponesa resgatou a complexidade do campo. A partir dos significados dessa vida compreendeu e elaborou o que apreendeu da complexidade da vida da metrópole. Situada no tecido dos acontecimentos, construiu novos significados reiterando como o conhecimento vai sendo adquirido à medida que novas informações são ancoradas em representação, conceitos e ideias que tem disponíveis em sua estrutura cognitiva (AUSUBEL, 1963).

Da dúvida, fez-se a descoberta: vislumbraram-se possibilidades sobre o espaço de vida e de produções culturais, artísticas e sociais do campo capixaba. Evidenciou-se que para apreciar as produções artísticas do homem do campo capixaba era requerida consideração à complexidade de sua vida. A utilização de padrões de arte e estilos consolidados de outros contextos culturais deixaram de ser vistos como referência de excelência, mas sim como possível obstáculo para alcançar os significados e sentidos das produções capixabas.

\section{Considerações finais}

A arte exposta em Museus, Teatros, Cinema, Galerias, Bibliotecas, no Brasil, esta disponível apenas para um grupo seleto da população, uma vez que esses diferentes espaços são inacessíveis para maioria da população que reside nos centros urbanos e muito mais, ainda, aos povos do campo.A arte popular apresentada na exposição "Teimosia da Imaginação", trouxe para a metrópole parte daquilo que representam os camponeses em sua produção artístico-cultural muito desconhecida e desvalorizada. Os povos do campo, neste texto representados pelos artesãos da ArtBoa, desenvolvem no dia a dia o que foi descrito no texto como a originalidade da aprendizagem significativa que é a ênfase dada ao processo relacional do sujeito, situado em seu contexto, com pessoas e objetos que o cercam. 
Todo o trabalho desenvolvido se dá de forma cooperativa, desde a escolha da matéria-prima, retirada da natureza com muito respeito e comprometimento com o meio ambiente, passando pela criação das peças até a comercialização das mesmas, sempre considerando o outro no processo de aprendizagem de todos os envolvidos.

\section{Referências}

AUSUBEL, D. P. The psychology of meaningful learning. New York, USA: Grune and Stratton, 1963.

JIANOU, I. Rodin. Paris, França: Arted, Editions d'Art, 1970.

PEREIRA, C.; NARDIN, H. O. Cruzamentos De Códigos Culturais e Estético: um olhar sobre a tecelagem artesanal. Florianópolis, SC: ANPAP 17o Encontro Nacional da Associação Nacional de Pesquisadores em Artes Plásticas - 19 a 23 de agosto, 2008.

MORIN, E. A cabeça bem-feita: repensar a reforma, reformar o pensamento. 14. ed. Tradução de Eloá Jacobina. Rio de Janeiro: Bertrand Brasil, 2008. Original em francês, 1999.

MORIN, E. Introdução ao pensamento complexo. Tradução de Eliane Lisboa. 3. ed. Porto Alegre: Ed. Sulina, 2007. Original em francês 2005.

MORIN, E. Política de civilização e problema mundial. Revista FAMECOS. Porto Alegre, n. 5, nov. 1996. Semestral.

SALGADO, M.; FRANCISCATTI, K. V. S. Contraponto entre arte, artesanato e trabalho: a falsa diferenciação e a atrofia da fantasia. 2012. Disponível em: $<$ http://www.ip.usp.br/laboratorios/lapa/ve rsaoportugues/2c43a.pdf $>$. Acesso em: 11 abr. 2012. 